\title{
Continuous positive airway pressure improves vascular function in obstructive sleep apnoea/ hypopnoea syndrome: a randomised controlled trial
}

\author{
M D Cross, ${ }^{1}$ N L Mills, ${ }^{2}$ M Al-Abri, ${ }^{1}$ R Riha, ${ }^{1}$ M Vennelle, ${ }^{1}$ T W Mackay, ${ }^{1}$ D E Newby, ${ }^{2}$ \\ N J Douglas ${ }^{1}$
}

${ }^{1}$ Department of Sleep Medicine, University of Edinburgh, Edinburgh, UK; ${ }^{2}$ Centre for Cardiovascular Science, University of Edinburgh, Edinburgh, UK

Correspondence to:

Dr M Cross, The University of Edinburgh, Chancellor's Building, Edinburgh EH16 4SB, UK: melanie.cross@ed.ac.uk

Received 26 March 2007 Accepted 2 December 2007 Published Online First 4 April 2008

\section{ABSTRACT}

Background: The obstructive sleep apnoea/hypopnoea syndrome (OSAHS) is associated with hypertension and increased cardiovascular risk, particularly when accompanied by marked nocturnal hypoxaemia. The mechanisms of these associations are unclear. We hypothesised that OSAHS combined with severe nocturnal hypoxaemia causes impaired vascular function that can be reversed by continuous positive airways pressure (CPAP) therapy.

Methods: We compared vascular function in two groups of patients with OSAHS: 27 with more than $204 \%$ desaturations/h (desaturator group) and 19 with no 4\% and less than five $3 \%$ desaturations/h (non-desaturator group). In a randomised, double blind, placebo controlled, crossover trial, the effect of 6 weeks of CPAP therapy on vascular function was determined in the desaturator group. In all studies, vascular function was assessed invasively by forearm venous occlusion plethysmography during intraarterial infusion of endothelium dependent (acetylcholine 5-20 $\mu \mathrm{g} / \mathrm{min}$ and substance P 2-8 pmol/min) and independent (sodium nitroprusside $2-8 \mu \mathrm{g} / \mathrm{min}$ ) vasodilators.

Results: Compared with the non-desaturator group, patients with OSAHS and desaturations had reduced vasodilatation to all agonists ( $p=0.007$ for all). The apnoea/hypopnoea index and desaturation frequency were inversely related to peak vasodilatation with acetylcholine $(r=-0.44, p=0.002$ and $r=-0.43$, $p=0.003)$ and sodium nitroprusside $(r=-0.42$, $p=0.009$ and $r=-0.37, p=0.02$ ). In comparison with placebo, CPAP therapy improved forearm blood flow to all vasodilators $(p=0.01)$.

Conclusions: Patients with OSAHS and frequent nocturnal desaturations have impaired endothelial dependent and endothelial independent vasodilatation that is proportional to hypoxaemia and is improved by CPAP therapy. Impaired vascular function establishes an underlying mechanism for the adverse cardiovascular consequences of OSAHS.

The obstructive sleep apnoea/hypopnoea syndrome (OSAHS) is caused by upper airways obstruction during sleep leading to hypopnoea or apnoea events. This leads to a symptom complex characterised by sleepiness and impaired cognitive function in conjunction with loud snoring. ${ }^{1}$ The arousals at the terminations of apnoeas and hypopnoeas are associated with transient rises in blood pressure. ${ }^{2}$ Obstructive sleep apnoea is associated with sustained hypertension in animal models $^{3}$ and in clinical epidemiological ${ }^{4}$ and interventional ${ }^{5}{ }^{6}$ studies. The elevation in blood pressure is most marked in those with more severe sleep related hypoxaemia. Recent evidence indicates that OSAHS is associated with an increased risk of cardiovascular $^{6}$ and cerebrovascular disease. ${ }^{78}$

The mechanism of the association between OSAHS, hypertension and cardiovascular disease is unclear. OSAHS is associated with increased sympathetic tone both in association with arousals from sleep ${ }^{9}$ and during daytime wakefulness. ${ }^{10} 11$ This could also be associated with activation of the renin-angiotensin-aldosterone system, ${ }^{12}$ alteration of baroceptor control, ${ }^{9}$ oxidative stress, ${ }^{13}$ increased inflammatory responses ${ }^{14}$ and increased hypercoagulability. ${ }^{15}$

Altered endothelial and vascular function may be the important link between OSAHS and cardiovascular disease. Current contradictory evidence reports either no effect, ${ }^{16}$ impaired endothelium dependent vasodilatation, ${ }^{17}$ impaired endothelium independent vasodilatation ${ }^{18}$ or even vasoconstriction. ${ }^{16}$ These findings are limited because of small group sizes ( $\mathrm{n}=8-10$ per group), lack of correlation with nocturnal hypoxaemia and variable use of control groups.

The aims of this study were to determine whether endothelial function is altered in patients with OSAHS and whether potential alterations in endothelial function correlate with the degree of sleep related hypoxaemia. Finally, we sought to establish the reversibility of any alterations in vascular function by using a double blind, randomised, placebo controlled, crossover trial of continuous positive airways pressure (CPAP) therapy.

\section{METHODS}

\section{Subjects}

Fifty-one patients with OSAHS, Epworth Sleepiness Score $>10$, aged 34-62 years participated in this study. Patients with clinical evidence of atherosclerotic vascular disease, asthma, respiratory failure or an inter-current illness were excluded from the study. OSAHS was diagnosed on the basis of symptoms, an Epworth Sleepiness Score $^{19}>10$ and an apnoea-hypopnoea index (AHI) of greater than $15 / \mathrm{h}$ on overnight polysomnography. Patients were stratified as desaturators (two major symptoms of OSAHS, AHI $>15$, $>20$ of $4 \%$ desaturations/h) or non-desaturators (two major symptoms of OSAHS, AHI $>15,<5$ of $3 \%$ desaturations $/ \mathrm{h}$ and no $4 \%$ desaturations $/ \mathrm{h}$ ). 
Figure 1 Study protocol. CPAP, continuous positive airways pressure; OSAHS, obstructive sleep apnoea/ hypopnoea syndrome.

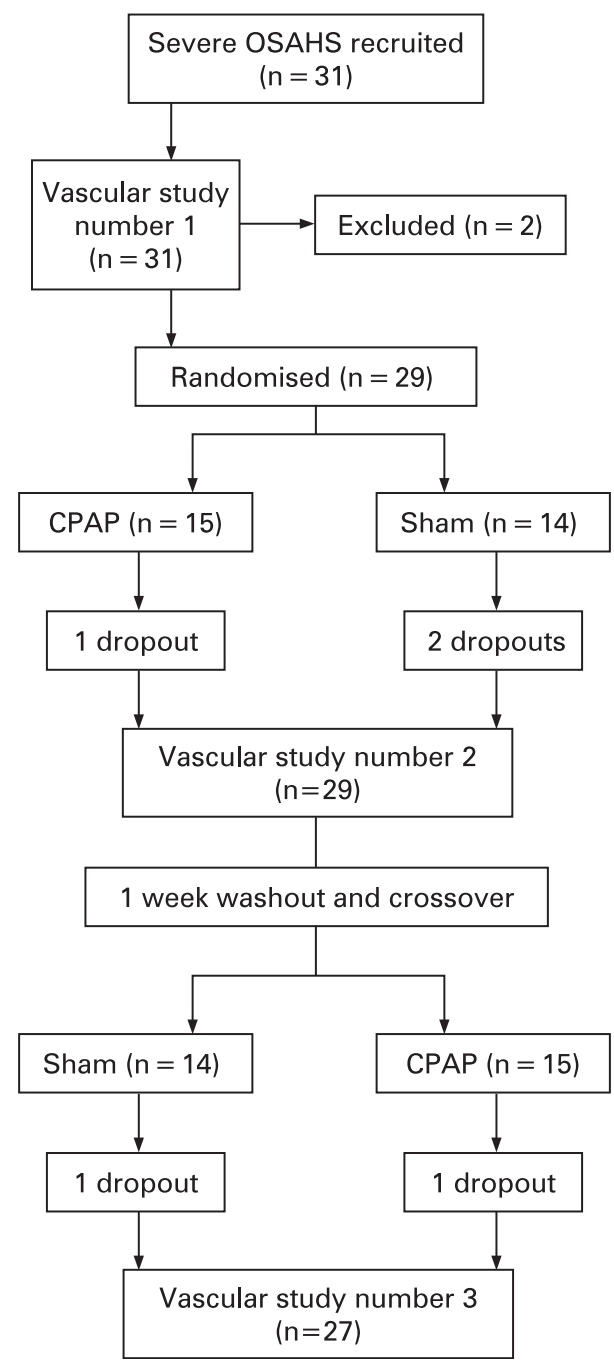

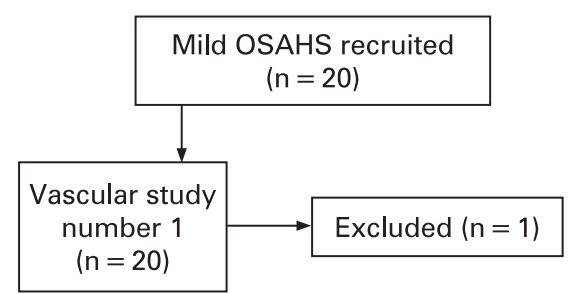

\section{Study design}

Study 1: Comparison of baseline vascular function in desaturators versus non-desaturators

All patients with OSAHS $(\mathrm{n}=51)$ attended for a screening visit that included a clinical history, physical examination and polysomnography. Desaturators and non-desaturators were identified a priori according to the polysomnographic findings from an inpatient sleep study, and all were invited to attend for a vascular assessment: 27 desaturators and 19 non-desaturators completed the study protocol (fig 1).

Study 2: Randomised placebo controlled trial of CPAP in desaturators Patients with OSAHS and significant nocturnal desaturation $(\mathrm{n}=27)$ had inhospital CPAP autotitration using a ResMed Spirit (ResMed, Poway, California, USA). The next morning they were randomised in a double blind, crossover study to receive 6 weeks of CPAP at the fixed pressure determined from the CPAP titration, and 6 weeks of sham CPAP with a 1 week washout period between treatment periods. Patients underwent a repeat vascular assessment at the end of both treatment phases (fig 1). Patients and researchers were blinded to the randomised treatment allocation.

\section{Vascular assessment}

All patients abstained from alcohol for $24 \mathrm{~h}$ and from food, tobacco and caffeine containing drinks for at least $4 \mathrm{~h}$ before each vascular study. Studies were carried out in a quiet temperature controlled room maintained at $22-24^{\circ} \mathrm{C}$ with subjects lying supine.

Patients underwent brachial artery cannulation with a 27 standard wire gauge steel needle under controlled conditions. Following a $30 \mathrm{~min}$ baseline saline infusion, acetylcholine at 5 , 10 and $20 \mu \mathrm{g} / \mathrm{min}$ (endothelium dependent vasodilator; Clinalfa AG, Bubendorf, Switzerland), substance P at 2, 4 and 8 pmol/ min (endothelium dependent vasodilator; Clinalfa $A G$ ) and sodium nitroprusside at 2,4 and $8 \mu \mathrm{g} / \mathrm{min}$ (endothelium independent vasodilator; David Bull Laboratories, UK) were infused for $6 \mathrm{~min}$ at each dose. The three vasodilators were separated by $20 \mathrm{~min}$ saline infusions and given in a randomised order, although this order was kept constant on each visit for each individual subject.

Forearm blood flow was measured in the infused and noninfused arms by venous occlusion plethysmography using mercury-in-silastic strain gauges, as described previously. ${ }^{20}$ Supine heart rate and blood pressure in the non-infused arm were monitored at intervals throughout each study using a semiautomated non-invasive oscillometric sphygmomanometer.

\section{Data analysis and statistics}

Plethysmographic data were determined as described previously. ${ }^{11}$ All data were analysed, finalised and locked by researchers blind to treatment type before treatment codes 
Table 1 Baseline characteristics of desaturating and non-desaturating patients with obstructive sleep apnoea/hypopnoea syndrome

\begin{tabular}{|c|c|c|c|}
\hline & $\begin{array}{l}\text { Desaturators } \\
(\mathrm{n}=27)\end{array}$ & $\begin{array}{l}\text { Non- } \\
\text { desaturators } \\
(n=19)\end{array}$ & p Value \\
\hline Age $(y)$ & $48(2)$ & $50(2)$ & 0.24 \\
\hline $\operatorname{Sex}(M / F)$ & $26 / 1$ & $18 / 1$ & $0.065^{*}$ \\
\hline Apnoea-hypopnoea index & $63(5)$ & $20(1)$ & $<0.0001$ \\
\hline Cigarette smokers & 6 & 7 & $0.28^{*}$ \\
\hline Diabetes mellitus & 1 & 0 & $0.40^{*}$ \\
\hline Hypertension & 7 & 4 & $0.70^{*}$ \\
\hline Hypercholesterolaemia & 8 & 6 & $0.89^{*}$ \\
\hline Weight $(\mathrm{kg})$ & $115(5)$ & $91(3)$ & 0.0001 \\
\hline Body mass index $\left(\mathrm{m}^{2} / \mathrm{kg}\right)$ & $37(1)$ & $30(1)$ & 0.0003 \\
\hline \multicolumn{4}{|l|}{ Drugs } \\
\hline Aspirin & 1 & 2 & $0.82^{*}$ \\
\hline Statin & 2 & 2 & $0.71^{*}$ \\
\hline$\beta$ Blocker & 3 & 2 & $0.95^{*}$ \\
\hline ACE inhibitor & 0 & 0 & $0.0^{*}$ \\
\hline Heart rate (bpm) & $64.7(12)$ & $72(3.8)$ & 0.04 \\
\hline Systolic blood pressure (mm Hg) & $143.2(3.3)$ & $143.4(4.64)$ & 0.97 \\
\hline Diastolic blood pressure (mm Hg) & $80.4(2.02)$ & $81.4(2.9)$ & 0.78 \\
\hline Infused FBF (ml/100 ml tissue/min) & $3.9(0.5)$ & $3.4(0.2)$ & 0.25 \\
\hline Non-infused FBF (ml/100 ml tissue/min) & $3.5(0.4)$ & $3.2(0.2)$ & 0.65 \\
\hline
\end{tabular}

were assigned to the data set. Continuous variables are reported as mean (SEM). Statistical analyses were performed with GraphPad Prism (Graph Pad Software) using analysis of variance (ANOVA) with repeated measures and two tailed Student's t test where appropriate.

\section{RESULTS}

\section{Study 1: Desaturators versus non-desaturators}

Desaturators had greater AHI than non-desaturators (63 (5) vs 21 (1); $p<0.0001)$. The patient groups were otherwise well matched except for body mass index, where the desaturators were more obese (37 (1) vs 30 (1) $\mathrm{m}^{2} / \mathrm{kg} ; \mathrm{p}=0.0003$ ). There were no differences in resting heart rate, blood pressure or baseline forearm blood flow between desaturators and nondesaturators (table 1).

Acetylcholine, substance $\mathrm{P}$ and sodium nitroprusside caused a dose dependent increase in forearm blood flow in all patients $(p<0.001)$. The increase in blood flow was blunted in desaturators compared with non-desaturators (fig 2) for each vasodilator: acetylcholine $(p<0.001)$, substance P $(p=0.007)$ and sodium nitroprusside $(p<0.001)$. Maximal vasodilatation was negatively correlated with AHI (fig $3 \mathrm{~A}-\mathrm{C}$ ) and desaturation frequency (fig 3D-F).

As the desaturators were heavier than the non-desaturators, a post hoc analysis was performed in which the five heaviest desaturators and four lightest non-desaturators were excluded-these deletions were made without knowledge of the patient's vascular function. While the resulting groups (22 desaturators, 15 non-desaturators) had similar body mass indices (34.2 (SEM 1.1) and $31.4(0.9) \mathrm{kg} / \mathrm{m}^{2} ; \mathrm{p}=\mathrm{ns}$ ), vasodilatation remained impaired in the desaturators compared with the non-desaturators: acetylcholine $(p=0.0002)$, substance $P$ $(p=0.009)$ and sodium nitroprusside $(p=0.005)$.

\section{Study 2: Randomised, placebo controlled trial}

Treatment with CPAP or sham CPAP for 6 weeks did not affect resting heart rate, blood pressure or baseline forearm blood flow (table 2). On an intention to treat basis, compliance for the CPAP limb of the study was $4.49(0.4) \mathrm{h}$, and compliance for the sham CPAP limb of the study was $3.08(0.48) h(p=0.015$, two tailed $t$ test).

Intrabrachial infusions of acetylcholine, substance $\mathrm{P}$ and sodium nitroprusside caused dose dependent increases in forearm blood flow at each visit $(p<0.001)$ that was unaffected by sham CPAP (data not shown). In comparison with results after sham CPAP, treatment with CPAP for 6 weeks improved forearm blood flow to all vasodilators (fig 4): acetylcholine $(p=0.002)$, substance $P(p=0.01)$ and sodium nitroprusside $(p=0.003)$.

\section{DISCUSSION}

We have demonstrated that patients with OSAHS have markedly impaired vascular function that is proportional to the degree of hypoxaemia. Using a rigorous double blind, randomised, placebo controlled, crossover trial, we have further demonstrated that CPAP therapy resulted in a clear improvement in vascular function in patients with OSAHS. Together these important and novel findings suggest that vascular dysfunction is related to disease severity in OSAHS, and that effective treatment with CPAP can improve vascular function and consequently reduce the associated cardiovascular complications.
Figure 2 Infused (solid line) and noninfused (broken line) forearm blood flow in desaturating (closed symbols) and nondesaturating (open symbols) patients with obstructive sleep apnoea/hypopnoea syndrome during intrabrachial infusion of acetylcholine, substance $P$ and sodium nitroprusside: for all dose-responses in the infused arm, $p<0.001$. For desaturating versus non-desaturating patients (ANOVA): acetylcholine $(p<0.001)$, substance $P(p=0.007)$ and sodium nitroprusside $(p<0.001)$. Values are mean $(95 \% \mathrm{Cl})$.
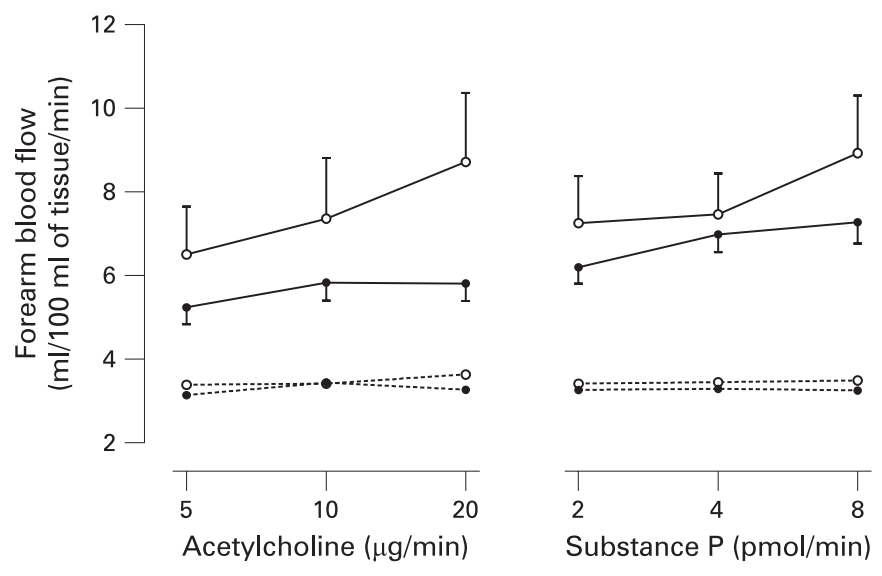

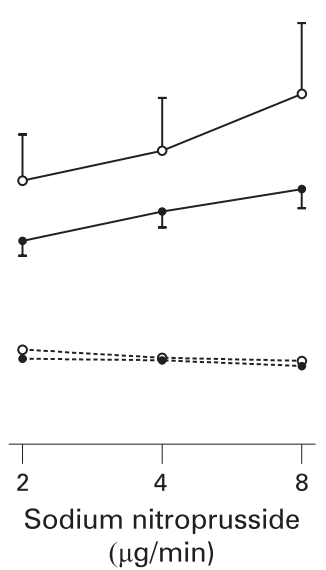



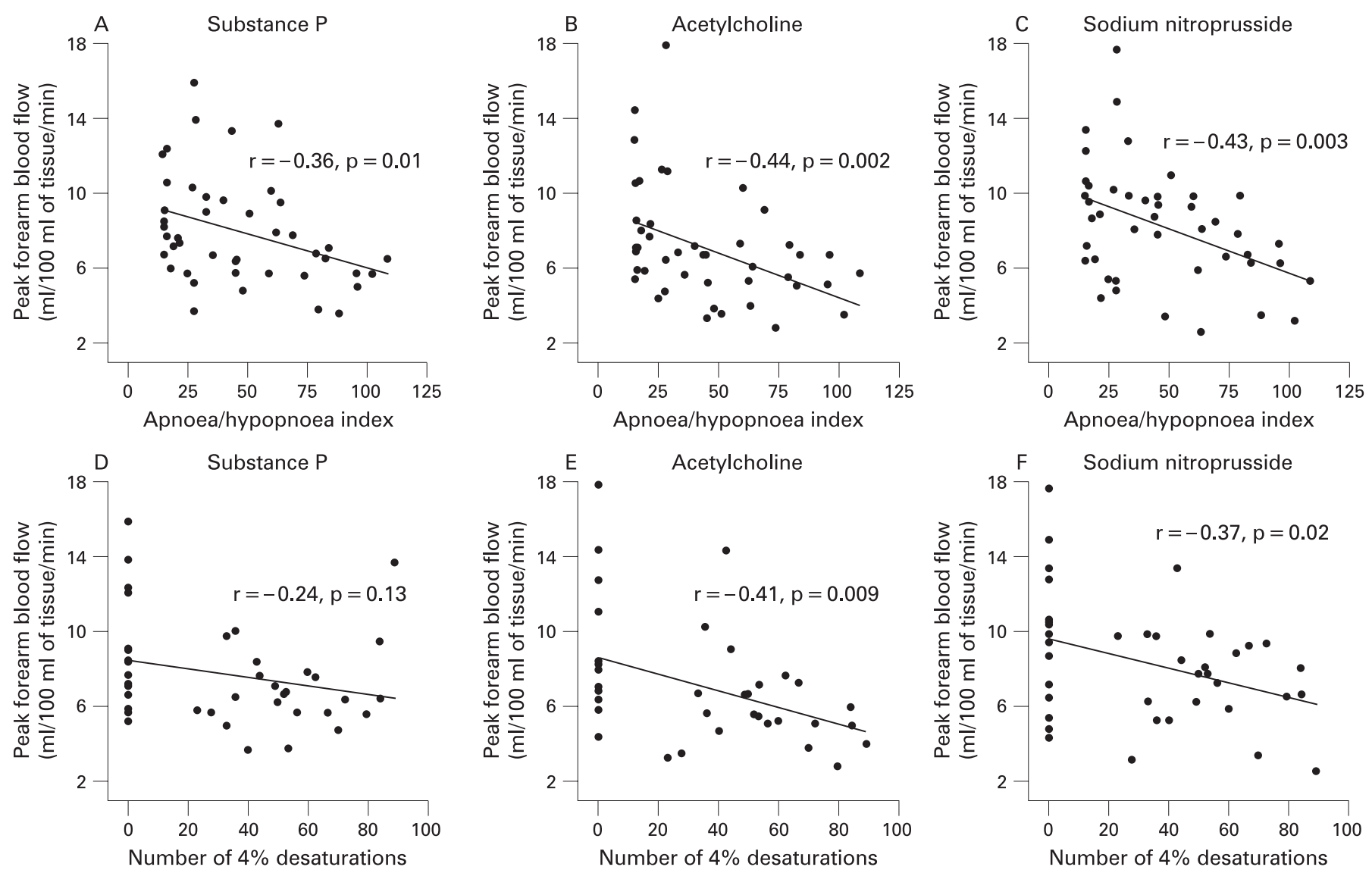

Figure 3 Peak vasodilatation following infusion of substance $P$, acetylcholine and sodium nitroprusside was negatively correlated with both apnoea/ hypopnoea index $(\mathrm{A}-\mathrm{C})$ and desaturation frequency $(\mathrm{D}-\mathrm{F})$.

\section{Vascular dysfunction in OSAHS}

Our findings add to the evidence base that OSAHS is associated with vascular dysfunction and disease. Our study represents the largest investigation of vascular function in patients with OSAHS. The study population is $\sim 3$-fold larger than previous studies $^{15-17}$ and we have incorporated the use of two distinct endothelium dependent vasodilators. We have found a marked impairment in endothelium dependent and independent vascular reactivity in patients with OSAHS. Given the associations with hypoxaemia, our findings also suggest that severity of OSAHS directly affects vascular reactivity with greater impairment in more severely desaturating patients (fig 3).

Animal models have suggested that hypoxia, ${ }^{21}$ cyclical hypoxia and reoxygenation ${ }^{22}$ can have detrimental vascular effects; existing evidence ${ }^{23}$ suggests that vascular dysfunction can be induced by hypoxia in susceptible individuals. We

Table 2 Haemodynamic variables in patients at baseline and following 6 weeks of continuous positive airways pressure (CPAP) or sham CPAP treatment

\begin{tabular}{lcccc}
\hline & $\begin{array}{l}\text { Baseline } \\
(\mathbf{n = 2 7 )}\end{array}$ & $\begin{array}{l}\text { Sham } \\
(\mathbf{n = 2 7})\end{array}$ & $\begin{array}{l}\text { CPAP } \\
(\mathbf{n = 2 7 )}\end{array}$ & p Value \\
\hline Heart rate (bpm) & $64.7(1.2)$ & $65.5(2.6)$ & $63.9(2.3)$ & 0.37 \\
Systolic blood pressure (mm Hg) & $143.2(3.3)$ & $144.8(3.7)$ & $141(3.1)$ & 0.07 \\
Diastolic blood pressure (mm Hg) & $80.4(2.02)$ & $82.3(1.7)$ & $82.3(1.9)$ & 0.84 \\
Infused FBF (ml/100 ml tissue/min) & $3.4(0.2)$ & $3.4(0.2)$ & $3.5(0.2)$ & 0.29 \\
Non-infusedFBF (ml/100 ml tissue/min) & $3.2(0.2)$ & $3.5(0.2)$ & $3.1(0.2)$ & 0.40 \\
\hline
\end{tabular}

Values are reported as mean (SEM), two tailed paired $t$ test.

FBF, forearm blood flow. therefore speculate that the adverse vascular effects of OSAHS are mediated through nocturnal hypoxaemia.

\section{Effect of CPAP on vascular dysfunction in OSAHS}

Previous studies into the effect of treatment in OSAHS on vascular function have been either observational ${ }^{24-26}$ or had no placebo control. ${ }^{242527}$ We have conducted a double blind, randomised, placebo controlled, crossover trial that maximises the study power while minimising the potential for treatment bias. Our findings provide robust evidence that OSAHS related dysfunction of vasomotor tone is reversible with CPAP within 6 weeks of initiating therapy. This provides a potential explanation for our own ${ }^{5}$ and other ${ }^{6}$ observations that CPAP lowers blood pressure most in severely desaturating patients with OSAHS.

In a subgroup of patients with OSAHS and hypertension, blood pressure does not fall appropriately during sleep ("nondippers"). ${ }^{28}$ This may lead to increased left ventricular mass ${ }^{29}$ and an increased risk for cardiovascular events. ${ }^{30}$ These patients have most to gain from CPAP use, by avoiding the vascular dysfunction associated with OSAHS, mediated through repetitive hypoxaemia.

\section{Mechanism of vascular dysfunction}

Impaired endothelium dependent and independent function in the forearm vascular bed is associated with an increased risk of acute cardiovascular events, including cardiac death. ${ }^{31}$ We initially hypothesised that endothelial dependent mechanisms alone were responsible for vasomotor dysfunction in the 
Figure 4 Infused (solid line) and noninfused (broken line) forearm blood flow in patients following 6 weeks of treatment with sham (closed symbols) and continuous positive airways pressure (CPAP) (open symbols) during intrabrachial infusion of acetylcholine, substance $P$ and sodium nitroprusside: for all dose-responses in the infused arm, $\mathrm{p}<0.001$. For sham versus CPAP (ANOVA): acetylcholine $(p=0.002)$, substance $P(p=0.01)$ and sodium nitroprusside $(p=0.003)$. Values are mean $(95 \% \mathrm{Cl})$.

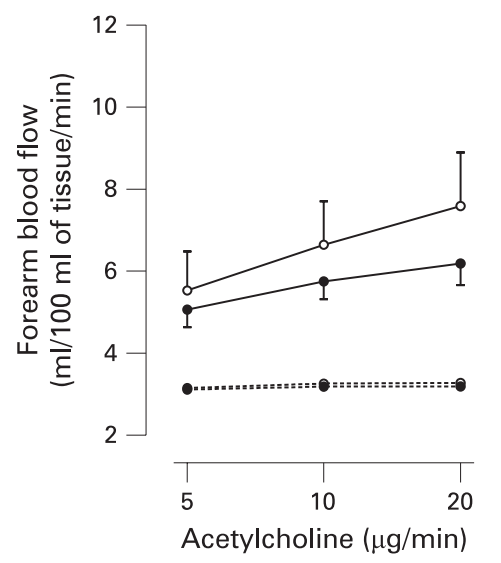

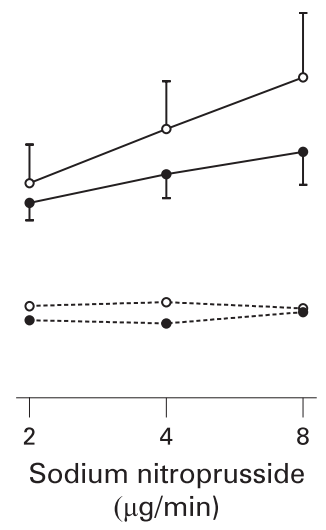

Substance $\mathrm{P}(\mathrm{pmol} / \mathrm{min})$
OSAHS. However, our findings suggest that both endothelium dependent and independent mechanisms are impaired. It is unclear whether the observed impairment is mediated primarily by the endothelium or is a result of vascular smooth muscle dysfunction.

Reduced nitric oxide bioavailability ${ }^{32}$ in the presence of increased systemic vascular oxidative stress $^{33}$ is an attractive hypothesis. Here, increased consumption of nitric oxide, whether it is endogenously derived from endothelial nitric oxide synthase or from an exogenous source, such as sodium nitroprusside, would explain the observed impairment to both endothelial dependent and independent vasodilators. The endothelium is a major target of oxidative stress, which plays an important role in the pathophysiology of cardiovascular disease. In OSAHS, recurrent episodes of hypoxaemia followed by reoxygenation may trigger oxidative stress and endothelial damage. Urinary 8-isoprostane concentrations are elevated in patients with moderate-severe OSAHS, suggesting that the syndrome is associated with systemic oxidative stress. ${ }^{34}$ Furthermore, 8-isoprostane levels correlate with the duration of nocturnal hypoxia, and fall following treatment with CPAP. However, the occurrence and role of oxidative stress in OSAHS is controversial $1^{13} 335^{36}$ and measuring systemic oxidative stress is notoriously difficult.

Alternative explanations for the pattern of vascular impairment should also be considered. Compared with wakefulness, heart rate, blood pressure and sympathetic nerve traffic to the vasculature decrease progressively throughout sleep. ${ }^{29}{ }^{37}$ In contrast, sympathetic activity and blood pressure increase during arousals. Thus the autonomic nervous system and its response to sleep and arousals may play a key role in the mechanism of vascular dysfunction in OSAHS. Sleep disordered breathing and hypoxia may contribute to the elevation of endothelin-1 concentrations in patients with OSAHS induced hypertension. ${ }^{12} 3338$

\section{Study limitations}

A limitation to the study included the absence of a normal control group. It would not have been feasible to find weight matched healthy volunteers who did not have some degree of irregular breathing during sleep. Obesity and insulin resistance are associated with vascular dysfunction, ${ }^{39}$ and this could be partly responsible for our observed differences. We took the pragmatic approach of using a non-desaturating OSAHS group as a control.

We did not include non-desaturators in the treatment trial, and therefore cannot comment on the potential benefits to vascular function of therapy in these patients. We focused on the desaturating group in this trial as our objective was to determine whether any vascular function abnormality was reversible and we decided a priori that changes with CPAP were most likely to be demonstrated in the more hypoxaemic group.

We acknowledge the inevitable mismatch in body mass index that resulted from consecutively recruiting desaturating and non-desaturating patients. However, our post hoc analysis matching for body mass index (fig 5) and by post hoc
Figure 5 Infused (solid line) and noninfused (broken line) forearm blood flow in desaturating (closed symbols) and nondesaturating (open symbols) patients with obstructive sleep apnoea/hypopnoea syndrome (OSAHS) during intrabrachial infusion of acetylcholine, substance $P$ and sodium nitroprusside: for all doseresponses in the infused arm, $\mathrm{p}<0.001$. For desaturating versus non-desaturating (ANOVA): acetylcholine $(p=0.0002)$, substance $P(p=0.009)$ and sodium nitroprusside $(p=0.005)$. Values are mean $(95 \% \mathrm{Cl})$.
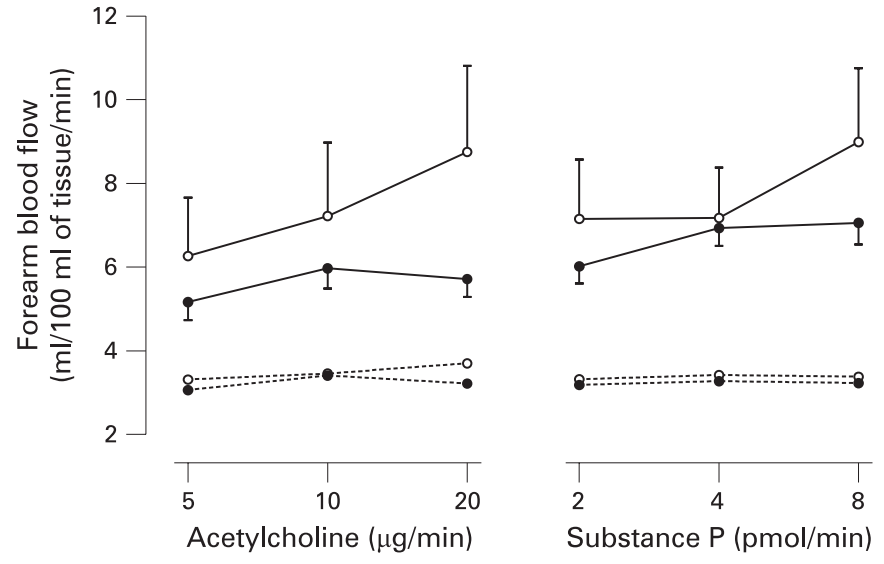
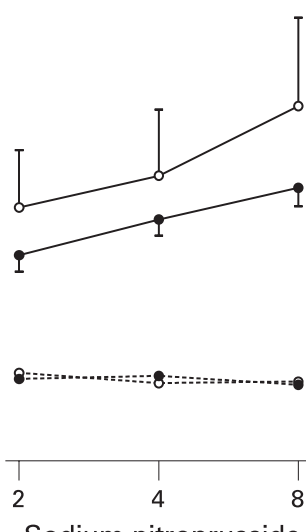

Sodium nitroprusside $(\mu \mathrm{g} / \mathrm{min})$ 
multivariate analysis strongly suggest that weight was not a factor in the difference in vascular responses between the groups.

There was no statistically significant carryover effect but also no measurements were made until 7 weeks after crossover1 week washout plus 6 weeks of treatment - and the known effects of CPAP wear off within a few days.

There is no ideal placebo for CPAP. CPAP improves patency of the upper airway and is the treatment of choice for patients with OSAHS by pneumatically splinting open the upper airway. Sham CPAP, using a similar device altered to deliver a subtherapeutic airway pressure, is arguably the best placebo. ${ }^{6}$ However, sham CPAP use was significantly lower than actual $\mathrm{CPAP}$ and this suggests that patients received positive reinforcement from the benefits of actual CPAP use. The clear difference in vascular function after active rather than sham CPAP is robust evidence of abnormal function in OSAHS that is reversible with effective treatment.

\section{CONCLUSIONS}

Patients with OSAHS and frequent nocturnal desaturations have markedly impaired endothelial dependent and independent vasodilatation. In these patients, treatment with CPAP for 6 weeks resulted in marked improvements in vascular function. These findings suggest that disease severity is an important modulator of vascular function, and that CPAP treatment may play an important role in reducing the cardiovascular complications associated with nocturnal apnoeas.

Acknowledgements: We thank all the staff in the Wellcome Trust Clinical Research Facility, Edinburgh, for their assistance with the studies.

Funding: MDC was supported by the Wellcome Trust Director's Support Fund and the BMA Josephine Landsell Grant (2004). The study was supported by a British Heart Foundation Project Grant (PG/02/078/14122).

Competing interests: None.

Ethics approval: Ethics approval was obtained.

\section{REFERENCES}

1. Engleman HM, Martin SE, Deary IJ, et al. Effect of continuous positive airway pressure treatment on daytime function in sleep apnoea/hypopnoea syndrome. Lancet 1994:343:572-5.

2. Davies RJ, Belt PJ, Roberts SJ, et al. Arterial blood pressure responses to graded transient arousal from sleep in normal humans. J Appl Physiol 1993;74:1123-30.

3. Brooks D, Horner RL, Kozar LF, et al. Obstructive sleep apnea as a cause of systemic hypertension. Evidence from a canine model. J Clin Invest 1997;99:106-9.

4. Hla KM, Young TB, Bidwell T, et al. Sleep apnea and hypertension. A populationbased study. Ann Intern Med 1994;120:382-8.

5. Faccenda JF, Mackay TW, Boon NA, et al. Randomized placebo-controlled trial of continuous positive airway pressure on blood pressure in the sleep apnea-hypopnea syndrome. Am J Respir Crit Care Med 2001;163:344-8.

6. Pepperell JC, Ramdassingh-Dow S, Crosthwaite N, et al. Ambulatory blood pressure after therapeutic and subtherapeutic nasal continuous positive airway pressure for obstructive sleep apnoea: a randomised parallel trial. Lancet 2002;359:204-10.

7. Arzt M, Young T, Finn L, et al. Association of sleep-disordered breathing and the occurrence of stroke. Am J Respir Crit Care Med 2005;172:1447-51.

8. Dyken ME, Somers VK, Yamada T, et al. Investigating the relationship between stroke and obstructive sleep apnea. Stroke 1996;27:401-7.

9. Narkiewicz K, Pesek CA, Kato M, et al. Baroreflex control of sympathetic nerve activity and heart rate in obstructive sleep apnea. Hypertension 1998;32:1039-43.

10. Somers VK, Dyken ME, Clary MP, et al. Sympathetic neural mechanisms in obstructive sleep apnea. J Clin Invest 1995;96:1897-904.
11. Hedner J, Darpo B, Ejnell $\mathrm{H}$, et al. Reduction in sympathetic activity after long-term CPAP treatment in sleep apnoea: cardiovascular implications. Eur Respir J 1995; 8:222-9.

12. Moller DS, Lind P, Strunge B, et al. Abnormal vasoactive hormones and 24-hour blood pressure in obstructive sleep apnea. Am J Hypertens 2003;16:274-80.

13. Grebe $\mathbf{M}$, Eisele HJ, Weissmann N, et al. Antioxidant vitamin C improves endothelial function in obstructive sleep apnea. Am J Respir Crit Care Med 2006;173:897-901.

14. Ohga E, Tomita $T$, Wada $\mathrm{H}$, et al. Effects of obstructive sleep apnea on circulating ICAM-1, IL-8, and MCP-1. J App/ Physiol 2003;94:179-84.

15. Shimizu M, Kamio K, Haida M, et al. Platelet activation in patients with obstructive sleep apnea syndrome and effects of nasal-continuous positive airway pressure. Tokai J Exp Clin Med 2002;27:107-12.

16. Kraiczi $\mathbf{H}$, Hedner J, Peker $Y$, et al. Increased vasoconstrictor sensitivity in obstructive sleep apnea. J Appl Physiol 2000;89:493-8.

17. Kato M, Roberts-Thomson P, Phillips BG, et al. Impairment of endothelium-dependent vasodilation of resistance vessels in patients with obstructive sleep apnea. Circulation 2000;102:2607-10.

18. Carlson JT, Rangemark C, Hedner JA. Attenuated endothelium-dependent vascular relaxation in patients with sleep apnoea. J Hypertens 1996;14:577-84.

19. Johns MW. A new method for measuring daytime sleepiness: the Epworth sleepiness scale. Sleep 1991;14:540-5.

20. Newby DE, Wright RA, Labinjoh C, et al. Endothelial dysfunction, impaired endogenous fibrinolysis, and cigarette smoking: a mechanism for arterial thrombosis and myocardial infarction. Circulation 1999;99:1411-15.

21. Toporsian M, Govindaraju K, Nagi M, et al. Downregulation of endothelial nitric oxide synthase in rat aorta after prolonged hypoxia in vivo. Circ Res 2000;86:671-5.

22. Yokoyama S, Korthuis RJ, Benoit JN. Hypoxia-reoxygenation impairs endotheliumdependent relaxation in isolated rat aorta. Am J Physiol 1996;270:R1126-31.

23. Berger MM, Hesse C, Dehnert C, et al. Hypoxia impairs systemic endothelial function in individuals prone to high-altitude pulmonary edema. Am J Respir Crit Care Med 2005;172:763-7

24. Duchna HW, Guilleminault C, Stoohs RA, et al. Vascular reactivity in obstructive sleep apnea syndrome. Am J Respir Crit Care Med 2000;161:187-91.

25. Ohike Y, Kozaki K, lijima K, et al. Amelioration of vascular endothelial dysfunction in obstructive sleep apnea syndrome by nasal continuous positive airway pressurepossible involvement of nitric oxide and asymmetric NG, NG-dimethylarginine. Circ J 2005;69:221-6.

26. Lattimore JL, Wilcox I, Skilton M, et al. Treatment of obstructive sleep apnoea leads to improved microvascular endothelial function in the systemic circulation. Thorax 2006;61:491-5.

27. Ip MS, Tse HF, Lam B, et al. Endothelial function in obstructive sleep apnea and response to treatment. Am J Respir Crit Care Med 2004:169:348-53.

28. O'Brien E, Sheridan J, O'Malley K. Dippers and non-dippers. Lancet 1988;2:397.

29. Verdecchia P, Schillaci G, Borgioni C, et al. Gender, day-night blood pressure changes, and left ventricular mass in essential hypertension. Dippers and peakers. Am J Hypertens 1995;8:193-6.

30. Willich SN, Linderer T, Wegscheider $\mathrm{K}$, et al. Increased morning incidence of myocardial infarction in the ISAM Study: absence with prior beta-adrenergic blockade. ISAM Study Group. Circulation 1989;80:853-8.

31. Munger RG, Weniger BG, Warintrawat $\mathrm{S}$, et al. Sudden death in sleep of South-East Asian refugees. Lancet 1986;2:1093-4.

32. In MS, Lam B, Chan LY, et al. Circulating nitric oxide is suppressed in obstructive sleep apnea and is reversed by nasal continuous positive airway pressure. Am J Respir Crit Care Med 2000;162:2166-71.

33. Lavie L, Vishnevsky A, Lavie P. Evidence for lipid peroxidation in obstructive sleep apnea. Sleep 2004;27:123-8.

34. Minoguchi K, Yokoe T, Tazaki T, et al. Increased carotid intima-media thickness and serum inflammatory markers in obstructive sleep apnea. Am J Respir Crit Care Med 2005; 172:625-30.

35. Svatikova A, Wolk R, Lerman LO, et al. Oxidative stress in obstructive sleep apnoea Eur Heart J 2005;26:2435-9.

36. Barcelo A, Barbe F, de la Peña M, et al. Antioxidant status in patients with sleep apnoea and impact of continuous positive airway pressure treatment. Eur Respir $J$ 2006;27:756-60.

37. Somers VK, Dyken ME, Mark AL, et al. Sympathetic-nerve activity during sleep in normal subjects. N Engl J Med 1993;328:303-307.

38. Yao $\mathbf{X}$, Sun $Y$, Chu $Y$, et al. The changes of some vasoactive substances after operation in patients with obstructive sleep apnea-hypopnea syndrome. Lin Chuang Er Bi Yan Hou Ke Za Zhi 2005;19:937-8.

39. Steinberg H0, Chaker $\mathrm{H}$, Leaming $\mathrm{R}$, et al. Obesity/insulin resistance is associated with endothelial dysfunction. Implications for the syndrome of insulin resistance. J Clin Invest 1996:97:2601-10. 